\title{
Apontamentos sobre as categorias analíticas de Joachim Burmeister (1564-1629)
}

\author{
Cassiano Barros \\ Universidade do Estado de Santa Catarina
}

\begin{abstract}
Resumo
As categorias analíticas de Joachim Burmeister são consideradas uma das primeiras iniciativas na história da música ocidental para se promover o conhecimento de uma obra de música. No entanto, a quantidade de referências que as situam na raiz da descendência de uma prática analítico-musical é diretamente proporcional à sua incompreensão e a sua desvalorização como ferramenta para se conhecer o repertório para o qual elas foram concebidas. Isso porque parecem não responder às questões de muitos críticos e analistas modernos que, diferentemente de Burmeister, ignoram a sua contribuição para a identificação dos artifícios compositivos e a constituição de modelos para imitação. Considerando que essas categorias respondiam às questões relevantes para os músicos do século $\mathrm{XVI}$, este artigo tem o objetivo de trazer apontamentos que contribuam para compreendê-las em seus próprios termos, recuperando referências de seu horizonte de sentido, articulando-as e ressignificando-as em nosso tempo presente.
\end{abstract}

Palavras-chave: Poética Musical. Joachim Burmeister. Retórica Musical. Análise Musical.

\section{Joachim Burmeister e suas obras}

Joachim Burmeister foi um músico alemão que passou a maior parte de sua vida na cidade de Rostock, atuando como mestre de capela (kantor) nas igrejas da cidade entre 1589 e 1593 e como professor (collega classicus) na escola local, responsável por ensinar a gramática e a composição do latim, de 1593 até seu falecimento, em 1629 (RIVERA; RUHNKE, 2001). Entre 1599 e 1609, Burmeister publicou cinco tratados dedicados à teoria, à prática e à poética musical, a saber: Observações sobre a Poética Musical (Hypomnematum musicae poeticae, 1599), Música Improvisada (Musica autoschediastikē, 1601), Música prática ou o método da arte de cantar (Musicae practicae sive artis canendi ratio, 1601) extrato da quarta parte do tratado Música Improvisada, Poética Musical (Musica poética, 1606), e A música teórica de Henricus Brucaeus (Musica theorica Henrici Brucaei, 1609) (RIVERA; RUHNKE, 2001).

Sua produção musical é singela e pequena para os padrões da época, devido, talvez, ao pouco tempo dedicado ao ofício musical. Seus textos, contudo, especialmente aqueles dedicados à poética musical, destacam-se como síntese e referência do pensamento musical 
protestante de sua época. Servem ao cumprimento da função da música no exercício da religião, ou seja, ao exercício da palavra divina como forma de salvação. Apresentam elementos de teoria musical, prescrições poéticas e ferramentas de exegese da música, a fim de contribuir para a formação de músicos (compositores, cantores e instrumentistas) e ouvintes (BURMEISTER, 1993, p. 6, 7). Seus textos evidenciam o processo histórico de formulação de uma teoria em construção, na medida em que sua sucessão reformula, adapta, acumula e consolida os conceitos, categorias, procedimentos e ideias que ele elabora. Constituem esse caminho o Observações da Poética Musical (Hypomnematum musicae poeticae, 1599), o Música Improvisada (Musica autoschediastikē, 1601) e o Poética Musical (Musica poética, 1606), dentre os quais o último é aquele que apresenta a versão final daquilo que assumimos hoje como sendo a concepção de Burmeister sobre a poética musical vigente em sua época1.

A definição de uma poética musical era uma ideia relativamente recente na época de Burmeister. Surge pela primeira vez no texto intitulado Música (Musica) de Nikolaus Listenius (c. 1510-?), publicado em Nurenberg em 1549. Nesse texto, Listenius propõe uma tripartição da música, na qual cada ramo é definido por um fim específico: a musica theorica tem como fim o conhecimento adquirido por meio da razão; a musica practica tem como fim a ação em si de produzir som; e a musica poetica tem como fim a obra musical consumada e registrada, de tal modo que sua existência independa da existência de seu criador (LISTENIUS, 1549, f.a3v). Os dois primeiros ramos eram considerados conforme a orientação medieval das artes liberais. O terceiro ramo, por sua vez, foi concebido para comportar a sistematização do processo de composição musical, ou, dito de outra forma, a partir do referencial aristotélico, para comportar a sistematização do hábito produtivo musical orientado pela razão, dedicado a gerar as coisas que podem ser um modo ou de outro e cujo princípio está no criador e não na coisa criada (ARISTÓTELES, 2005, p. 185-186).

A musica poetica surge como uma consequência dos valores da cultura humanista somados à concepção luterana da música. Por um lado, é entendida como um mecanismo regrado de representação operado pelo artífice eticamente comprometido; por outro, é a arte própria do homem poeta - criador - aquele que revela o contato com o divino, na medida em que reproduz, sob a forma de discurso humano, a "poesia" de Deus (BARTEL, 1997, p. 19).

Em conformidade com a proposta agostiniana, os luteranos conceberam a música como um dom de Deus, de todos, o mais apto a transmitir a palavra Dele. Tem como matéria as Sagradas Escrituras, entendidas como poesia elevadíssima, a obra de criação por excelência, o grande poema do Artista Criador, que o juntou a esse outro poema que é o mundo. A tópica

\footnotetext{
${ }^{1}$ Dentre os estudos sobre as obras de Burmeister, destacam-se os de Palisca (2001), Rivera, in: Burmeister (1993), e Ruhnke (1955). No Brasil, destaca-se o estudo de Ambiel (2010).
} 
que relaciona o mundo - como livro de Deus - e as Sagradas Escrituras estende-se na relação com a palavra e a música do homem, tanto mais sagradas quanto mais próximas dos textos divinos (BARTEL, 1997, p. 4).

Nesse contexto protestante, no qual se assume o conhecimento da música religiosa como forma de acesso ao texto bíblico e, a partir daí, ao exercício religioso, o desenvolvimento de técnicas para o estudo da música e a incorporação desse estudo ao currículo escolar é assumido como compromisso de estado, como forma de se reafirmar e consolidar a própria estrutura social e cultural e as instâncias de poder político-religioso. Nesse sentido, a partir de Listenius, diversos outros músicos se dedicaram a constituir, ao longo do tempo, uma extensa produção dedicada à poética musical, configurando uma tradição própria do contexto luterano.

Na sequência dessa tradição, o músico Heinrich Faber (1500-1552), em 1550, em seu tratado intitulado Introdução à Música Prática ( $A d$ musicam practicam introductio), também publicado em Nuremberg, igualmente concebe a música como uma disciplina tripartida em seus ramos teórico, prático e poético, e define esse último como aquele que "modela o poema musical"2. Já em 1563, Gallus Dressler (1533-1581), em seu texto intitulado Preceitos de Poética Musical (Praecepta Musicae Poeticae) define a poética musical como "a técnica de modelar o poema musical”3, e avança em sua definição, diferenciando a poética da teoria e da prática musical e especificando a que tipo de produção ele se refere:

[A poética] distingue-se das partes restantes da música. A theorica examina atentamente, a practica canta. Esta [a poética] verdadeiramente compõe novas harmonias, e resta a obra completa mesmo depois de morto seu autor. A poética musical é dupla, evidentemente o contraponto improvisado e a composição. $\mathrm{O}$ contraponto improvisado (como o mesmo nome indica) é a pronunciação improvisada por diferentes vozes, extemporânea e instigada sobre o canto de alguém. Esta é a mais usual junto aos estrangeiros do que conosco, e que depende mais dos usos/costumes do que das regras [originadas a partir da composição] e que carece de menos vícios [deixada aqui para se tratar da composição], pois não se registra por escrito e não é comum transmiti-la aos estudantes ${ }^{4}$.

Em sua definição, Dressler claramente retoma a ideia de Listenius ao reafirmar a permanência da obra criada após a morte de seu compositor a partir do registro escrito dela, integra essa ideia àquela de Faber, ao restringir a produção à música da poesia e mais

\footnotetext{
2 Poetica fingit musica carmina. (FABER, 1550. p. f.B2r).

${ }^{3}$ Quid est Musica Poetica? Est ars fingendi musicum carmen. (DRESSLER, 1563, p. 216)

${ }^{4}$ Differt a reliquis Musicae partibus. Theorica considerat, practica canit. Haec vero novas harmonias componit, et opus absolutum vel authore mortuo post se relinquit. Poetica musica duplex est, videlicet sortisatio et compositio. Sortisatio ut ipsa appellatio indicat est subita et impulsa supra cantum aliquem per diversas voces extemporalis pronuntiatio. Haec apud exteros [magis] usitatior est quam apud nos, et cum ex usu magis quam praeceptis pendeat [et oriatur ex compositione] minimeque vitiis careat [omissa hac ad compositionem accedamus] nam scripto comprehendere et studiosis tradere non est usitatum. (DRESSLER, 1563, p. 216-217)
} 
especificamente à poesia que é posta em música, e avança no sentido de diferenciar a produção a que se refere daquela resultante do contraponto improvisado.

Em 1606, em seu tratado intitulado Poética Musical (Musica Poetica), Burmeister define seu objeto de estudo nos seguintes termos:

A poética musical, que Euclides chama de melopoeia, que seria o tratamento harmônico de um assunto, com a finalidade de adornar os argumentos de acordo com o que se trata, é aquela parte da música que ensina a compor o poema musical, unindo sons melódicos em harmonia, ornamentados com diversos afetos de períodos, a fim de mover as almas e os corações humanos ${ }^{5}$.

Nessa definição, Burmeister dá um passo adiante em relação a seus antecessores, associando a poética musical ao conceito grego de melopoeia que, segundo Pereira (2001, p. 18), define a relação entre poesia e música, assumindo a origem da segunda na primeira, na medida em que a música "não preexiste independentemente da palavra, mas antes radica nela, inspira-se e brota a partir dela, constituindo ambas (música e poesia) um todo designado por melopoeia - composição melódica". Nessa combinação, a forma de uso da linguagem verbal condiciona a forma de uso da música, pelo princípio do decoro, conforme se adornam "os argumentos de acordo com o que se trata" (BURMEISTER, 1993, p. 16). Nesses termos, podemos considerar que a palavra aplicada em sentido próprio, em textos simples, de cunho didático, por exemplo, comportaria música igualmente simples, ao passo que à palavra aplicada em sentido figurado equivaleria uma música proporcionalmente figurada, desviada do uso simples e comum. Essas medidas de uso da linguagem, que determinam seu grau de simplicidade e figuração, assim como os modos em que esses graus são representados, seja por meio de palavras e/ou sons musicais, são convenções que qualificam as aparências de verdade consideradas válidas no contexto histórico-cultural em que se realizam. É nesse sentido que Burmeister faz referência à junção de "sons melódicos em harmonia", circunscrevendo seu discurso à produção da música polifônica, textura própria do estilo vigente, que se caracteriza pela combinação de várias melodias simultâneas, que soem de maneira harmoniosa, conforme às regras do contraponto. Igualmente, podemos tomar a ornamentação da música com diversos afetos de períodos, algo que não aparece nas definições anteriormente citadas, e que pode ser entendido aqui como os desvios da forma mais simples de expressão, empregadas conforme processo analógico próprio que relaciona o gesto sonoro ao seu efeito no ouvinte, como forma de potencializá-lo no âmbito da apresentação de uma ideia completa, ou seja, no âmbito de um periodus. Esses afetos se materializariam no discurso musical na forma de figuras de expressão, ou seja, formas

\footnotetext{
${ }^{5}$ Musica Poetica, quam Euclides [melopoiian] nominat, definitque esse usum harmonicae tractationi subjectorum, ad decorum propositi argumenti, est illa Musicae pars, quae carmen musicum docet conscribere, conjungendo sonos Melodiarum in Harmoniam, varijs periodorum affectionibus exornatam, ad animos hominum cordaque in varios motus flectenda. (BURMEISTER, 1993, p. 16).
} 
particulares de representação de ideias que, nas palavras de Burmeister, "se distanciam da razão composicional simples para assumir e vestir, com virtude, um caráter de ornamento ${ }^{6}$." Nesse sentido, os afetos de períodos seriam as figuras empregadas pelos compositores para representar o sentido do texto nessas unidades gramático-retórico-musicais, os períodos. A relação entre afetos e períodos será tratada com maior atenção mais adiante neste texto.

Enfim, resta tratar da causa final da produção musical, que é definida por Burmeister como o movimento das almas e dos corações humanos. Sabemos, pelas artes retóricas ${ }^{7}$, que esse movimento resulta da persuasão para as causas que o orador tem por tarefa defender. Neste caso, no exercício de seu ofício poético, o músico-orador luterano atua como instrumento das instituições que o empregam - a Corte e a Igreja - com a finalidade de promover a missão delas em seus respectivos espaços de atuação: a primeira, de natureza temporal, civil e secular, e a segunda, de natureza atemporal, espiritual e religiosa (LUTERO, 2017, p. 5-7). Assim, a causa final da ação de produzir música, para além da obra produzida, conforme proposto por Listenius e Dressler, reside na função sócio-político-religiosa que ela desempenha no contexto cultural em que está inserida. Nesse contexto, a ação poéticomusical cumpriria seu fim último e cobraria seu sentido na medida em que os movimentos da alma e do coração orientassem ações virtuosas e a elevação da alma, constituídas em hábitos por sua repetição e frequência (cf. ARISTÓTELES, 2005, p. 74, 77, 79, 107, 308, 309). Esses hábitos, por sua vez, contribuem para a edificação moral do indivíduo conforme às determinações religiosas e para a manutenção da ordem social que, na concepção luterana, é também de origem religiosa. Neste ponto, cabe esclarecer que, segundo Skinner (1996, p. 140), Lutero, seguido de Melanchton e outros protestantes, considera que o homem, por sua natureza corrompida pela queda adâmica, não é capaz de distinguir o bem do mal, tendendo sempre ao descaminho na ordenação da vida. Diante disso, afirma a origem divina dos poderes seculares, como os do rei e dos príncipes, que fazem uso da espada a serviço de Deus para aplacar a maldade e a selvageria e conservar a paz e a ordem social, por meio das quais se realizam os modos de vida na terra (LUTERO, 2017, p. 21-22).

\section{O tratado Musica Poetica (1606) - seu contexto de produção e referências}

Conforme Rivera (BURMEISTER, 1993, p. 51), o tratado Musica Poetica foi escrito com a função de transmitir a músicos e compositores aspirantes uma doutrina amplamente aceita. Burmeister, na dedicatória de seu tratado, especifica suas intenções nos seguintes termos:

\footnotetext{
${ }^{6}$ Ornamentum sive figura musica est tractus musicus, [...] qui a simplici compositionis ratione discedit, et cum virtute ornatiorem habitum assumit et induit. (BURMEISTER, 1993, p.154-156)

${ }^{7}$ Vide Anônimo. Retórica a Herênio. São Paulo: Hedra, 2005. p. 59-60. ARISTÓTELES. Retórica. Lisboa: Imprensa Nacional Casa da Moeda, 2005. p. 97; QUINTILIANO, Marco Fábio. Instituição Oratória. Campinas: Editora da Unicamp, 2016.
} 
A fé me move a tratar do tema [a poética musical] apresentando preceitos, puxando minha orelha e me lembrando de que nenhuma arte liberal pode ser transmitida a alguém sem regras. Ela [a fé] me move a me abrir e a fazer crer que com ou sem a ajuda da natureza, imitação e prática, qualquer um pode elaborar uma compreensão da arte, uma vez que esteja amparado por um compêndio. De outra forma, natureza, imitação e prática, desacompanhadas dos textos instrucionais, não são capazes de conduzir ao domínio daquelas coisas que pertencem à arte, e nem a mestria será alcançada na falta de regras que eu considero essenciais a todo compêndio. A menos que sejam formuladas regras precisas, a arte para a qual a instrução é elaborada não será minimamente produzida, e assim ninguém alcançará um perfeito domínio dela. [...] A fim de resgatar a música desse destino [o desprezo decorrente de sua prática desregrada e descompromissada] tanto quanto eu puder - pois após longa consideração e atenção aos pedidos de Deus, eu compreendi que essa arte pode ser mais amplamente comunicada - eu não hesitei em escrever esses preceitos com a ajuda Dele e em organizá-los numa ordem precisa para o benefício de minha audiência. [...] Espero que vocês [cônsules e senadores do Governo de Rostock, patrocinadores da publicação] aceitem esse testemunho de minha intenção e determinação em ajudar zelosamente no aprimoramento do estudo e da prática da música, seja na escola ou na igreja, ou em qualquer outro lugar e tempo possível, assim como durante muitos anos eu cumpri minhas responsabilidades como mestre de capela. (BURMEISTER, 1993, p. 4-7).

Justificando seu trabalho como resultado do exercício da fé, Burmeister enfatiza a importância da sistematização do conhecimento para sua transmissão, especialmente na forma dos tratados, como o Musica Poetica. Relaciona esse conhecimento à natureza, ou seja, à inclinação natural do compositor para o exercício da técnica produtiva e à própria técnica, porquanto ela seja conhecimento e atividade especificamente humanos e próprios de sua natureza. Relaciona esse conhecimento também à imitação das formas autorizadas e válidas de se produzir, na perspectiva de se reafirmar o costume e a ordem consolidadas pelas instituições vigentes e o valor das próprias instituições; e finalmente relaciona-o à prática, ao fazer e refazer refletido, cotidianamente pensado, que conduz ao domínio da técnica. Burmeister afirma que esse conhecimento sistematizado resulta de longa consideração sua e ajuda divina. A longa consideração fica evidente na trajetória de suas publicações, que imprimem a formulação e reformulação de suas ideias ao longo do tempo e deixam claro a dedicação do autor ao seu objeto de estudos. Por outro lado, se essa declaração é tomada como artifício discursivo, constatamos que sua afirmação outorga valor às regras formuladas, uma vez que elas resultariam de extenso exame e estudo, qualificados pela ajuda divina. Essa qualificação, por sua vez, situa o autor e seu texto, por extensão, entre o elenco daqueles a quem a autoridade é outorgada, por analogia ao poder secular, para determinar o que se autoriza ou não fazer sobre determinada questão, neste caso, de natureza musical. Nesse sentido, a publicação de seu tratado, porquanto autorizada e financiada pelo Estado, constitui-se como instrumento definidor das práticas autorizadas, alinhadas à tradição instituída. Finalmente, Burmeister reitera sua intenção em contribuir para o aprimoramento do estudo e da prática da música, situando essas atividades na escola e na igreja, relacionando-os especificamente à educação de acordo com o currículo da escola 
latina (Lateinschule) e ao exercício religioso de acordo com as práticas e dogmas da igreja luterana.

O tratado de Burmeister faz referências a diversos autores, cujas ideias, conceitos, categorias, regras e técnicas são atualizados, transpostos, confirmados ou negados, configurando o texto em seu tempo como portador de múltiplas temporalidades que se sobrepõem na construção de seu sentido. Dentre os autores citados, encontram-se Platão, Aristóteles, Aristoxeno, Plutarco, Euclides, Quintiliano, Boécio, Erasmo de Roterdã e outros, que se somam a outras tantas referências não citadas, mas implícitas pelo contexto de onde o texto emerge, tais como L. Lossius, Ph. Melanchton, G. Zarlino, G. Gaffurio e outros identificados por Rivera (In: BURMEISTER, 1993, p. 46-47). Com essas referências, de influência teórica e poética, cruzam-se referências de natureza prática, pelas ilustrações e recomendações feitas pelo autor, tais como Orlando di Lasso, Clemens non Papa, Ivo de Vento, Alexander Utendal, Luca Marenzio, Alexander Utendal, Jacobus Regnart, Johannes Knöfel, Jacob Meiland, Antonio Scandello, André Pevernage, Leonhardt Lechner e Johann Dressler (BURMEISTER, 1993, p. 208-209).

O tratado Musica Poetica é organizado em dezesseis capítulos, que tratam de questões de natureza poética, prática e teórica. Os aspectos práticos e teóricos são considerados apenas nos termos daquilo que condiciona a produção musical e, assim, caracteriza-se no texto o seu objeto de estudo e reflexão. A análise musical é abordada no décimo quinto capítulo, como artifício poético, ou, dito de outra forma, como técnica de estudo do repertório musical que viabiliza a imitação, esta sim considerada um princípio poético que reafirma a função social da produção musical, a permanência das possibilidades válidas de uso da linguagem musical consolidadas pela tradição e o lugar das autoridades constituídas nas estruturas de poder vigentes. Nesse sentido, a proposta de Burmeister se alinha às demais propostas vigentes e referenciadas, não só na área da música, mas também nas demais linguagens, como podemos constatar no tratado de L. Lossius intitulado Questões dialéticas e retóricas de Felipe Melancton (Erotemata Dialecticae et Rhetoricae Philippi Melanthonis; 1600 , p. 242):

[A imitação] (de acordo com Quintiliano) ocorre quando, a partir dos autores dignos de leitura, toma-se a abundância de vocabulário, a variedade das figuras e o método de composição, e volta-se a mente para os exemplos de todas as suas virtudes. ${ }^{8}$

\footnotetext{
8 [Imitatio] est (ut ex Quintiliano colligitur) cum ex auctoribus lectione dignis, verborum copia sumitur, et varietas figurarum, ac componendi ratio, atque ad exemplum virtutum omnium mens dirigitur. (LOSSIUS, 1600, p. 242). Nesta definição, Lossius faz referência à definição de Quintiliano, presente na Instituição Oratória (X, 2, I), onde lemos: De imitatione. Ex his ceterisque lectione dignis auctoribus et verborum sumenda copia est et varietas figurarum et componendi ratio, tum ad exemplum virtutum omnium mens derigenda. Conforme já constatado em pesquisas anteriores, como a de Rivera (1993), por exemplo, este tratado de L. Lossius serviu de referência a Burmeister para a elaboração de sua poética musical.
} 
Lossius recupera as referências de Melancton e Quintiliano para a constituição de sua ideia sobre a imitação que, enquanto princípio criativo, não é uma invenção do século XVII, pois podemos encontrá-la formulada desde a poética aristotélica ${ }^{9}$, mas se renova nesse tempo pelas mãos de Burmeister e seus contemporâneos, que contrafazem as prescrições presentes nos tratados antigos de retórica atualizando-as. Merece atenção a semelhança das ideias de Burmeister e Lossius com o texto anônimo do século I a.C. intitulado Retórica a Herênio, onde lemos:

O orador deve ter invenção, disposição, elocução, memória e pronunciação. [...] Tudo isso poderemos alcançar por três meios: arte, imitação e exercício. Arte é o preceito que dá método e sistematização ao discurso. Imitação é o que nos estimula, com método cuidadoso, a que logremos ser semelhantes a outros no dizer. Exercício é a prática assídua e o costume de discursar. (Retórica a Herênio, 2005, p. 55).

Nesse texto, a imitação é apresentada como meio para o exercício da arte, que conduz à produção de símiles, quando acompanhada de arte, como os preceitos formulados no tratado de Burmeister, e exercício, como aquele também recomendado por esse autor para a formação em composição.

Burmeister chega ao século XXI como o pai da análise musical. Dunsby e Whittall (2011, p. 21-22), por exemplo, creditam a ele a formulação da primeira descrição e interpretação de uma obra musical completa, o moteto intitulado In me transierunt, de Orlando di Lasso, entendida como uma demonstração analítica resultante da aplicação da terminologia retórica à música. McCreless (2008, p. 854-855), por sua vez, reconhece o pioneirismo da análise musical elaborada por Burmeister e, por essa razão, o qualifica como fundador da prática analítica e da tradição de uma doutrina das figuras (Figurenlehre), identificada com Bartel (1997) como ferramenta de exegese musical.

Ainda que Burmeister ocupe um lugar de destaque nos textos contemporâneos sobre teoria e análise musical, a compreensão de seus textos, conceitos e ideias é ainda uma tarefa complexa e difícil, uma vez que o distanciamento histórico entre ele e nós, leitores do século $X X I$, é também um distanciamento cultural, que demanda reconhecimento de um amplo contexto, de referências e de estudos interdisciplinares que nos permitam recuperar as várias línguas que estão aprisionadas numa língua dominante no texto musical, assim como seus sentidos, suas técnicas de elaboração, disposição e invenção, especificando pressupostos filosóficos, poéticos, políticos, religiosos e históricos que nos possibilitem superar anacronismos e aceder às aparências de verdade vigentes em seu tempo, que validam seu próprio modo de pensar, perceber e atuar, sistematizando a formação produtiva em sua época.

\footnotetext{
9 Vide Aristóteles, 2017, p. 37-41.
} 


\section{As categorias analíticas de Joachim Burmeister}

Burmeister (1993, p. 200-201) define a análise musical como a investigação de uma poesia cantada (cantilena) modal e polifônica, por meio da divisão de seus afetos ou períodos, de maneira tal que "os artifícios com os quais cada um deles foi produzido possam ser estudados e adotados como modelo para imitação"10. Nessa definição, o autor delimita as qualidades do objeto de investigação, restringindo-o à música vocal, ou, por analogia, aquela instrumental que a imita, que se constitui conforme a um certo modo, a partir das possibilidades disponíveis no sistema modal vigente, e de forma polifônica, ou seja, a mais de uma voz. De forma inicial, podemos considerar que essas qualidades delimitam as possibilidades elementares de aparência de verdade reconhecidas como válidas no contexto em que o autor opera.

Essa definição avança na enumeração das cinco partes do processo analítico, assim denominadas: "1. Investigação do modo; 2. Investigação do gênero da melodia; 3. Investigação do tipo de polifonia; 4. Consideração da qualidade; 5 . divisão do poema em afetos ou períodos."11 Essas partes se definem a partir das próprias qualidades já destacadas inicialmente, enquanto abstrações generalizantes que emergem do repertório referenciado como categorias que permitem reconhecer, em cada caso, a forma particular de ocorrência dos materiais e técnicas postos em evidência para imitação.

Chama a atenção o fato de Burmeister intitular o capítulo dedicado ao estudo desse tema de Sobre a análise ou a disposição do poema musical (De Analysi sive Dispositione Carminis Musici), estabelecendo analogia entre os termos análise e disposição. Considerando a definição de análise e a ênfase na ideia da fragmentação do todo da obra em partes menores como forma de se alcançar os usos particulares dos artifícios compositivos, compreende-se a referência à ideia da disposição retórica, já elucidada por Rivera (In: BURMEISTER, 1993, p. 201). Aliás, há de se destacar que para além dessa primeira relação, mais direta, outra se coloca, na medida em que as características do processo dispositivo se aplicam, de forma inversa, ao processo analítico, tais como a consideração do gênero poético e musical e suas variações estruturais geradoras da verossimilhança própria de cada gênero, a consideração da funcionalidade de cada parte e a sujeição delas ao cumprimento do objetivo da obra, as possibilidades de combinação e articulação entre cada parte na construção do sentido da obra, a distribuição dos artifícios, técnicas e desvios de linguagem entre as partes e a

\footnotetext{
${ }^{10}$ Analysis cantilenae est cantilenae ad certum Modum, certumque Antiphonorum Genus pertinentis, et in suas affectiones sive periodos, resolvendae, examen quo artificium, quo unaquaeque periodus scatet, considerari et ad imitandum assumi potest. (BURMEISTER, 1993, p. 200-201).

11 Partes Analyseos constituuntur quinque 1. Modi inquisitio. 2. Generis Modulaminum: et 3. Antiphonorum indagatio. 4. Qualitatis consideratio. 5. Resolutio carminis in affectiones, sive periodos. (BURMEISTER, 1993, p. 200-201).
} 
dimensão delas, por si e entre si. Esses são aspectos que, dentre outros, se colocam como critérios analíticos e que, certamente, se colocam também como condições compositivas, na medida em que a análise não tinha outro fim se não aquele de subsidiar a emulação, ou seja, a própria composição. Nesse sentido, refuta-se as argumentações que encontram em Burmeister apenas prescrições elocutivas, tais como as de McCreless (2008), por exemplo.

$\mathrm{Na}$ medida em que essas categorias analíticas emergem do repertório, da forma como ele é percebido e compreendido em seu próprio tempo, e são constituídas com o fim específico de evidenciar as formas de uso dos artifícios comuns a ele, para a formação de músicos e não-músicos, podemos considerar o valor dessas categorias como ferramentas de acesso a ele hoje, apesar da distância histórica e cultural, desde que esse distanciamento seja considerado no nosso processo de aproximação e suas referências sejam recuperadas, relativizando e ampliando as possibilidades de percepção e compreensão desse repertório hoje.

A primeira categoria analítica, dedicada à investigação do modo, é definida por Burmeister como "a consideração daqueles aspectos que são essenciais para a compreensão da constituição e identificação do modo ${ }^{12}$, seja em relação à conexão já realizada das notas ou em relação às conexões de notas que estejam por ser realizadas." 13

Para Burmeister (1993, p. 121), modo é um tipo de medida do canto musical, que regula a melodia estabelecendo seus limites, ou seja, seu âmbito e suas possibilidades de condução melódica conforme as relações intervalares entre os diferentes graus da escala, e regula a harmonia definindo igualmente seus limites, mais especificamente as possibilidades de combinação de notas simultâneas, concebidas conforme as proporções numéricas.

\footnotetext{
12 Segundo Burmeister (1993, p. 122-125), as oitavas, em seu âmbito, contêm quatro alturas que produzem consonâncias, conforme as proporções harmônicas ou razões entre elas, de acordo com Pitágoras, Boécio e outros que trataram das proporções numéricas. A constituição do modo depende dessas mesmas alturas, que são o primeiro grau do modo (principium), o quarto e o quinto grau do modo (diatessaron et diapente respectivamente), e o oitavo grau do modo, que é a repetição do primeiro uma oitava acima. A consonância formada pelo primeiro grau da escala e uma de suas alturas intermediárias (quarto ou quinto grau) é chamada de base da disposição modal. Quando a base é constituída por uma quinta, o modo é chamado de autêntico, e quanto a base é constituída por uma quarta, o modo é chamado de plagal. O tenor configura os limites mais grave e agudo do modo, pelo primeiro e oitavo grau da escala com a qual sua melodia é elaborada. A parte do soprano (discantus) inicia sua oitava a partir do limite superior da oitava do tenor. O baixo (bassus) e o alto (altus) derivam o começo de sua oitava a partir do tom intermediário que divide a oitava do tenor (o quarto ou o quinto grau do modo) e estendem essa oitava até a nota de mesmo nome imediatamente acima ou abaixo de seu ponto de partida. Burmeister sintetiza essas observações numa regra: o ponto que uma voz tem como tom intermediário, a outra tem como limite. Esta coerência ou mistura de consonâncias e de oitavas que é gerada a partir daí é chamada de temperamento (temperamentum), e a oitava de cada voz é chamada de âmbito (ambitus).

13 De acordo com Burmeister (1993, p. 120-121), modo é um tipo de medida do canto musical. Num sistema específico, o modo governa e determina as consonâncias dentro de uma espécie de oitava (assim como as próprias oitavas). As oitavas são trazidas a uma agradável combinação complexa de acordo com um certo temperamento, e as consonâncias são arranjadas em proporção umas com as outras, de modo que se salvaguarde a natureza e o estado do modo. Os modos são duplos: eles regulam a melodia e a harmonia (melodimeter et harmonimeter). Regulam a melodia na medida em que estabelecem seus limites (âmbito da melodia e nota final) e regulam a harmonia estabelecendo igualmente seus limites (possibilidades de combinação simultânea de notas - formação de acordes -, conforme as proporções numéricas).
} 
Quarenta e oito anos antes, em seu tratado intitulado $A$ instituição harmônica (Le institutini harmoniche), publicado em Veneza em 1558, Zarlino define os modos musicais como "a razão, a medida ou a forma que nos previne de ir muito longe em qualquer coisa que fazemos, condicionando nossas ações com uma certa temperança ou moderação"14. Essa temperança ou moderação, por sua vez, é concebida como "uma certa maneira, ou ordem terminada e procedimento acabado, por meio da qual o ser de uma coisa é preservado em virtude da proporção que nela se encontra"15. Píndaro e Horácio são as autoridades citadas por Zarlino para validar sua definição ético-poética dos modos. Píndaro, em sua XIII Ode Olímpica, diz que "A cada situação, segue a justa medida: reconhecer o adequado é o melhor" (SILVA, 2015. p. 13), assim como Horácio que, na Sátira I, 1, 106-107, reconhece que "há certo modo em tudo: há certas raias entre as quais consiste, nem mais cá, nem mais lá, o justo acerto" (HORÁCIO, 2011, p. 25). Zarlino concebe a ideia dos modos musicais como parâmetros que orientam a realização de uma qualidade material, a proporcionalidade, como consequência do exercício de uma virtude ética, a temperança. Essa proporção, segundo Zarlino (1558, p. 293), nos agrada e nos dá proveito e, por essa razão, justifica sua necessidade.

A definição de Burmeister alinha-se à de seu antecessor veneziano pela perspectiva da medida que condiciona as possibilidades materiais de representação. Mas se afasta dele ao não relacionar as virtudes materiais da obra criada com o exercício das virtudes éticas do compositor, pelo menos não de forma explícita. Contudo, considerando o contexto luterano de onde emerge o texto de Burmeister e a função desse texto, de formação para a composição da música religiosa, é plausível pensar que essa relação estivesse implícita, uma vez que o compositor teria sua prática condicionada pelos meios e fins da instituição a que ele servisse, na qual os vícios de natureza ética provavelmente não seriam tolerados.

Ao propor o modo como categoria analítica, Burmeister reconhece a importância das medidas a ele relacionadas, tais como o âmbito das melodias e as proporções numéricas que condicionam as simultaneidades, no processo criativo e de análise das obras de música. Nesse sentido, é possível compreender a função do modo na invenção e na elaboração musical: enquanto parâmetro criativo, condiciona a produção musical, e enquanto parâmetro analítico, orienta a compreensão do discurso acabado.

Segundo Burmeister (1993, p. 198-199), "a investigação do gênero melódico é o exame do intervalo de quarta através do qual se estuda como ele é composto de intervalos menores

\footnotetext{
${ }^{14} \mathrm{Si} \mathrm{debbe} \mathrm{adunque} \mathrm{auertire,} \mathrm{che} \mathrm{questa} \mathrm{parola} \mathrm{Modo,} \mathrm{oltra} \mathrm{di} \mathrm{ogn'altra} \mathrm{sua} \mathrm{significatione,} \mathrm{che} \mathrm{sono} \mathrm{molte;} \mathrm{significa}$ propiamente la Ragione, cioè quella misura, o forma, che adoperiamo nel fare alcuna cosa, laqual ne astrenge poi a non passar più oltra; facendone operare tutte le cose con vna certa mediocrità, o moderatione. (ZARLINO, 1558, p. 293).

15 Imperoche tal mediocrità, o moderatione non è altro, che vna certa maniera, ouero ordine terminato, \& fermo nel procedere, per ilquale la cosa si conserua nel suo essere, per virtù della proportione, che in essa si ritroua; che non solo ne diletta, ma etiandio molto giouamento ne apporta. (ZARLINO, 1558, p. 293).
} 
e como ele é usado na obra e qual caráter ele assume"16. Em síntese, são usados apenas os gêneros diatônico e cromático. O primeiro é empregado de maneira conforme à estrutura natural dos modos e, o segundo, subverte-os com alterações cromáticas, especialmente para realizar o encadeamento de dois semitons sucessivos no contexto de uma mesma parte, em uma mesma frase. Nesse sentido, pode-se entender por que a escolha do gênero melódico condiciona a performance ou pronunciação do discurso musical: o gênero diatônico direciona a pronunciação para um rumo mais direto, imediato e simples, ao passo que o gênero cromático direciona a pronunciação para um desvio, uma alteração desse percurso simples e direto. Esse desvio, na medida em que corrompe a estrutura natural do modo, justifica-se pela força requerida da expressão, como alteração do próprio modo da fala, a fim de se obter ênfase ou destaque à ideia que se pretende comunicar. Entende-se, como Zarlino, que os modos são portadores de potencial expressivo, que se realiza em cada obra conforme a elaboração musical proposta pelo compositor. A alteração cromática de um modo, ou seja, o uso do gênero melódico cromático, pode sugerir uma ênfase ou alteração desse potencial expressivo, uma determinação mais precisa de sentido do discurso, necessidade de adequação da obra a condições específicas de recepção, dentre outras possibilidades.

Há de se considerar ainda que os gêneros melódicos se caracterizam como um material musical primário, com o qual as próprias melodias serão compostas, na medida em que determinam as próprias notas que constituirão os percursos melódicos das partes que constituem as obras de música. Sua definição antecede a constituição das melodias e a própria aplicação das figuras musicais no todo da obra. Nesse sentido, podemos compreender os gêneros melódicos como material próprio da invenção e, por essa razão, podemos compreender sua importância no processo de análise e estudo do repertório.

Burmeister (1993, p. 202-203, 200-201) define a terceira categoria analítica nos seguintes termos:

A investigação do tipo de polifonia é a comparação de sons em termos de duração e valor. A polifonia [Antiphonum], também chamada de contraponto, é a combinação harmoniosa de notas de valores iguais ou desiguais. Há três tipos de polifonia: simples [simplex], no qual todas as notas coincidem em igual valor; fraturado

\footnotetext{
16 O gênero melódico, que tem o tetracorde como característica (pois há quatro sons que seguem uns aos outros em sequência), configura-se pelo movimento dos pequenos intervalos dentro do intervalo de quarta (diatessaron), que condiciona sua forma de pronunciação/execução. Há três gêneros melódicos: 1. diatônico; 2. cromático; 3. enarmônico. O gênero diatônico é aquele cujo tetracorde está composto pela sequência de intervalos semitom pequeno, tom, tom, ou o reverso (o semitom pequeno é a menor metade de um tom. Pois um tom partido em suas menores partes, a saber, nove comas, não pode ser dividido em duas partes iguais. Se suas duas metades forem medidas, então uma necessariamente deverá ser maior e a outra menor. A menor será aquela que terá um coma a menos do que a maior, e a maior um coma a mais do que a menor). Este gênero melódico é usado em praticamente todos os motetos. O gênero cromático é aquele cujo tetracorde constitui-se da seguinte sequência intervalar: semitom pequeno, semitom grande, terça menor (semiditonum), ou sua ordem reversa. Seu uso na obra a seis vozes de Orlando di Lasso intitulada Concupiscendo é evidente. O gênero enarmônico é aquele cujo tetracorde é composto pela seguinte sequência intervalar: duas dieses (diesis é a metade de um semitom pequeno) e uma terça maior (ditonum). No tempo presente, esse gênero não é usado. Mas não há dúvida de que será usado no futuro. (BURMEISTER, 1993, p. 198-199).
} 
[fractum], no qual as notas são combinadas em valores diversos, e apenas poucas são coloridas de negro (semínimas, colcheias, semicolcheias e outros valores cuja cabeça da nota seja preenchida), enquanto a maioria não é (longa, breve, semibreve e mínima, figuras rítmicas cujas cabeças não são preenchidas); colorido [coloratum], no qual um número maior de notas coloridas de negro são combinadas com poucas notas não coloridas.

Nesta definição, Burmeister considera apenas a relação entre os valores de duração das notas que são combinadas entre si, enfatizando especificamente os tipos gráficos das figuras das notas. Enquanto a primeira categoria de polifonia distingue-se pela relação entre figuras de mesmo valor, qualquer que seja, as outras duas categorias distinguem-se pela maior ou menor incidência de figuras negras, quer dizer, figuras rítmicas com cabeças pintadas, tais como a semínima, a fusa e a semifusa ${ }^{17}$. Essa maior ou menor incidência de figuras negras no registro escrito desse repertório antigo a que Burmeister faz referência permite identificar nele a presença ou ausência de diminuições rítmicas ou coloraturas (coloraturis) e, a partir daí, compreender o uso da divisão rítmica como ornamento e como recurso de caracterização das vozes e sua independência. Em relação a essas últimas qualidades, Burmeister não associa a elas dois aspectos eminentemente contrapontísticos, que são o tipo de movimento entre as vozes e os tipos de intervalos possíveis de serem constituídos entre elas. Essas questões, ainda que concebidas como parte da técnica contrapontística, parecem não interferir na categorização da polifonia, que se orienta exclusivamente pelo aspecto rítmico da relação entre as vozes constituintes de uma obra musical.

Os tipos de intervalos e de movimentos entre as vozes são abordados nos capítulos 3 e 4 do Musica Poetica. Seu terceiro capítulo trata de forma suscinta da doutrina dos sons consonantes e dissonantes (De Sonorum Consonantium et Dissonantium Doctrina), retomando definições de Boécio de forma bastante simples e pragmática: consonância é o termo que qualifica a combinação de duas alturas que afeta suavemente o ouvido (BURMEISTER, 1993, p. 50-51); dissonância, por sua vez, é aquilo que atinge o ouvido como uma combinação dura e desagradável de alturas (idem, p. 54-55).

O quarto capítulo trata da combinação (Syntaxi) de consonâncias numa harmonia. Aqui, Burmeister se dedica efetivamente ao ensino da técnica do contraponto, descrevendo o método

\footnotetext{
17 De acordo com Burmeister (1993, p. 28-29), convencionalmente, a figura que representa a pulsação, ou a unidade de tempo musical (tactu) é a semibreve, e as demais figuras contém mais de uma unidade de tempo ou estão contidas nela. As figuras que contém a unidade de tempo são a breve (duas unidades na medida imperfeita de tempo e três unidades na medida perfeita de tempo), a longa (quatro unidades na medida imperfeita de tempo e seis unidades na medida perfeita de tempo) e a máxima (oito unidades na medida imperfeita de tempo e doze unidades na medida perfeita de tempo). As figuras que estão contidas na unidade de tempo são a mínima (na proporção de duas notas por unidade de tempo), a semínima (na proporção de quatro notas por unidade de tempo), a fusa (na proporção de oito notas por unidade de tempo) e a semifusa (na proporção de dezesseis notas por unidade de tempo). Cabe destacar que a fusa a que Burmeister se refere é conhecida atualmente em língua portuguesa como colcheia, e a semifusa como semicolcheia, como fica claro na ilustração de seu texto.
} 
de conjugar (ratio coniungendi) as notas de duas ou mais linhas melódicas para produzir um todo harmonioso. A conjugação de uma nota, segundo Burmeister (1993, p. 64-65), é a conexão ou combinação dela com outras duas notas situadas acima ou abaixo dela. Essa ideia da conjugação aplicada às notas musicais deriva da transposição da terminologia gramatical para a musical, a fim de explicar os princípios teórico-musicais, conforme indica Rivera (BURMEISTER, 1993, p. 65). Essa transposição da terminologia traz consigo, para a área de destino, sentidos do termo em seu uso original, e Burmeister confirma isso, na medida em que concebe, por exemplo, em cada conjugação sonora a existência de uma raiz, uma base (coniugata basis) que se preserva como referência da conjugação. Essa base constitui-se como uma espécie de essência sonora da representação musical, que assume sua forma final, ou seja, é conjugada, conforme sua função no discurso sonoro. Nesse sentido, podemos compreender a base da conjugação como matéria prima do artifício compositivo.

Numa outra perspectiva, podemos compreender essa base da conjugação como o fundamento do pensamento harmônico moderno, a partir da consideração de que todas as notas possuem potencial harmônico, ou seja, possuem potencial de conexão com outras notas, concebido numericamente, conforme às leis matemáticas consolidadas pela tradição medieval e contrafeitas pela corrente humanista seiscentista. Nessa mesma perspectiva se constituiu a prática do baixo contínuo, em desenvolvimento nesse mesmo período histórico. Sobre isso, Burmeister não comenta, mas sua forma de pensamento se assemelha bastante àquela proposta nos primeiros tratados publicados sobre o baixo contínuo nessa época, tais como os de Agostini Agazzari (Del sonare sopra'l basso con tutti li stromenti e dell'usu loro nel conserto; Siena: Domenico Falcini, 1607) e de Michael Praetorius (Syntagma Musicum III: De Basso Generali su Continuo; Wolfenbüttel, 1619), dentre outros.

A conjugação de uma nota resulta na combinação dela com sua terça maior ou menor acima, e mais a sua quinta justa ou a sexta maior ou menor. Assim, a conjugação da nota lá (A), por exemplo, resultaria nas seguintes possibilidades A-C-E, A-C\#-E, A-C-F e A-C\#-F\#. A nota lá é chamada de base, enquanto as demais notas sobrepostas a ela são chamadas de conjugações; a primeira, intermediária, sempre a um intervalo de terça maior ou menor sobre a base; e a segunda, superior, a um intervalo de quinta justa ou sexta maior ou menor sobre a base.

Burmeister apresenta de forma sintética, em tabelas, as possibilidades de conjugação de cada nota do Gamut ${ }^{18}$, indicando aos compositores novatos a necessidade de memorização delas. A união de conjugações, ou a conexão de consonâncias, constitui aquilo que Burmeister chama de operação sintática (operatio syntaxeos). Ela depende do

\footnotetext{
18 Gamut é a somatória da extensão vocal de todos os tipos de vozes de uso comum no período, do baixo ao soprano, usada como referência teórica para o estudo dos modos e das técnicas de leitura musical.
} 
conhecimento da teoria dos modos, pois esta estabelece os limites e as possibilidades para as conexões, e depende também das leis da sintaxe musical, que podem ser sintetizadas da seguinte maneira:

1. O compositor não precisa restringir sua atenção primeiro sempre à mesma voz, ou seja, ele pode iniciar seu trabalho ora pelo tenor, ora pelo soprano, ora pelo baixo, ora pelo contralto ou qualquer outra voz que esteja contida em sua obra;

2. No trabalho de construção, se a primeira voz a receber atenção não for o baixo, então o próximo passo é elaborar o baixo sob essa voz;

3. A melodia do tenor deve estar circunscrita ao âmbito de oitava do modo e deve-se evitar transgredi-lo com frequência;

4. A melodia do soprano (discantus) e do tenor deverão constituir-se de tal maneira que o tenor se movimente na região mediana da harmonia enquanto o soprano ocupa a região mais aguda, ambos movendo-se por graus conjuntos;

5. A melodia do baixo poderá progredir por passos maiores do que graus conjuntos;

6. A melodia do tenor deve terminar na nota mais grave de sua oitava. Considerando o que Burmeister propõe no capítulo 6 , a saber, que o tenor configura os limites mais grave e agudo do modo, pelo primeiro e oitavo grau da escala com a qual sua melodia é elaborada, subentende-se que o tenor estaria sempre elaborado no modo autêntico e que, ao terminar na nota mais grave de sua oitava, ele terminaria na nota final do modo; 7. As combinações mais perfeitas de notas serão aquelas usadas mais frequentemente na harmonia. As sextas imperfeitas, muito raramente;

8. O baixo, em relação com outra voz, não poderá formar qualquer tipo de intervalo de sexta por uma duração maior do que um tempo completo. Preferencialmente, essa combinação é permitida somente por metade ou por um quarto de tempo, e uma quinta ou uma oitava deveriam precedê-la e segui-la;

9. O intervalo de quarta não pode ser considerado entre as consonâncias que constituem a base da harmonia. Por isso, ele não pode ser colocado abaixo de uma combinação, mas apenas acima daquilo que cumpre propriamente a função de base da conjugação.

10. Solecismos ${ }^{19}$ devem ser evitados, pois obscurecem a harmonia e diminuem sua elegância 20 .

\footnotetext{
${ }^{19}$ Este termo também deriva da gramática e da retórica e, segundo Burmeister (1993, p. 78-79), significa a torção tortuosa (tortuosus flexus) de duas consonâncias, uma seguindo imediatamente a outra.

${ }^{20}$ Os solecismos constituem propriamente vícios de linguagem, barbarismos que, na linguagem musical, segundo Burmeister (1993, p. 78-101), atentam contra a melodia ou contra a harmonia. Contra a melodia, Burmeister cita 0 encadeamento de notas dissonantes entre si (aspeton intervallum ou disparatorum kakosynthesia) ou o encadeamento de notas muito distantes entre si (tonoparatasis), o que dificulta ou inviabiliza a execução da melodia. Contra a harmonia, Burmeister cita o movimento paralelo de consonâncias perfeitas (tautoëpia); o
} 
Cabe destacar daquilo que foi recuperado que a discussão sobre as categorias de intervalos, de conjugação e de sintaxe, conforme conduzida por Burmeister, não aborda a questão temporal, exceto como referência para aspectos específicos do processo criativo. Nesse sentido, fica evidente que o lugar do tempo no processo de análise reside na consideração da textura musical, conforme a relação entre as vozes que constituem o todo.

Outra característica apontada por Burmeister como objeto de atenção do processo analítico é a qualidade do sistema utilizado na produção musical, mais especificamente, a forma de uso do modo, se natural ou transposta ${ }^{21}$. Burmeister (1993, p. 136-137) considera válido um número restrito de possibilidades de transposição, a saber, apenas aquelas resultantes da realocação do modo uma quarta justa acima ou uma quinta justa abaixo de sua condição natural. Em qualquer caso, essas transposições resultam sempre no uso sistemático da alteração cromática si bemol como parte da escala do modo. Ainda segundo Burmeister (1993, p. 136-137), o uso da transposição em sua época é considerado algo novo e moderno, enquanto o uso dos modos em seu estado natural é considerado como antigo e mais tradicional. Para ele, "a maior parte das instruções sobre a arte da composição são orientadas pelo uso dos modos conforme sua qualidade primeira e mais antiga"22, e aqueles que desejam compor fazendo uso da qualidade mais nova e recente devem conhecer as possibilidades de transposição indicadas em seu texto. A justificativa para o uso do modo transposto é elaborada, em termos poéticos, pela necessidade de se fazer uso de um determinado registro mais grave ou mais agudo do que aquele disponível pelo modo em sua condição natural, conservando suas qualidades expressivas intrínsecas, uma vez que, na transposição, as relações intervalares entre os graus do modo seriam preservadas ${ }^{23}$.

movimento direto entre consonância perfeita e imperfeita (strophe); o uso de uníssonos e oitavas que comprometem a independência das vozes da obra (syzigia praecepts); o uso do intervalo de quarta como base de uma conjugação (catachresis quartae); a real ou potencial justaposição de acidentes distintos (sustenido e bemol, por exemplo) numa mesma conjugação (symploke); o dobramento da consonância imperfeita de uma conjugação (diplasis consonantiarum); a resolução imprópria de dissonâncias (kakokrypsis dissonantiarum); e a incompletude ou omissão de uma conjugação (elleima coniugati).

21 Toda a discussão sobre essa categoria analítica é construída sobre a consideração do tipo de tetracorde que qualifica o modo, conforme a perspectiva de Boécio (De institutione musica). Nesse sentido, trata de tetracordes separados (diezeugmenon) e tetracordes juntos (synemmenon), também chamados respectivamente de $B$ duralis e $B$ mollaris, que se caracterizam, o primeiro, pelo uso da nota diatônica Si natural e, o segundo, pelo emprego da alteração cromática Si bemol. O primeiro é chamado de tetracorde separado pois, segundo Burmeister (1993, p. 139), os tetracordes E-F-G-A e B-C-D-E, ambos constituídos pelas mesmas relações intervalares entre seus graus, guardam a distância de um tom entre si e estão, de fato, separados. A fim de resolver essa separação, os teóricos antigos dividiram esse intervalo de um tom ao meio e, fazendo uso do Si bemol, juntaram outro tetracorde ao primeiro, integrando os dois da seguinte maneira E-F-G-A / A-Bb-C-D, tomando a nota final de um como a nota inicial do outro, ambos também com as mesmas relações intervalares entre seus graus. Nessa perspectiva, este segundo, que faz uso da alteração cromática, é chamado de tetracorde junto, anexado, integrado (synemmenon). Esta qualidade do tetracorde, atualizada ao tempo de Burmeister, define a qualidade natural ou transposta do uso do modo.

${ }^{22}$ Doctrinae artis compositoriae maxima ex parte ad primam et antiquiorem illam qualitatem. (BURMEISTER, 1993, p. 136).

${ }^{23}$ Ao tratar sobre os usos dos modos, Burmeister (1993, p. 132-135) se vale da autoridade de Aristóteles, Aristoxeno e Plutarco para afirmar que cada modo possui suas próprias qualidades expressivas e, como exemplo, cita os modos Dórico e Hipodórico como os mais adequados para tratar dos assuntos sérios e graves; para os temas alegres e estimulantes, os modos Mixolídio e Hipomixolídio; para os temas trágicos e turbulentos, os modos 
Finalmente, a última categoria analítica proposta por Burmeister é de natureza estrutural, e propõe "a divisão de uma peça em afetos", o que "significa sua divisão em períodos"24. Para aqueles que se dedicam à análise musical, essa tarefa de fragmentar um todo em partes menores não é arbitrária e tampouco indiscriminada. Depende, principalmente, do reconhecimento dos critérios utilizados pelo compositor para estruturar sua obra e das marcas deixadas por ele nesse processo de estruturação. Em sua poética, Burmeister (1993, p. 106107) observa que a conclusão harmônica e melódica dos períodos é feita por meio de cadências (clausulae). Para ele, "nenhuma peça de música pode ser desprovida de cadências, pois a cadência está para a composição assim como a alma está para o corpo"25 e, por isso, recomenda aos iniciantes que não negligenciem a necessidade de cadências em suas obras se eles não quiserem que elas pareçam inanimadas. O lugar da cadência na música deve coincidir com as articulações no texto, tais como a vírgula, os dois pontos e o ponto final (BURMEISTER, 1993, p. 116-117). Em termos dialéticos, Burmeister considera que a cadência tanto finaliza o período precedente (terminus ad quem) quanto prepara o período subsequente (terminus a quo). Por seu valor intrínseco, enquanto artifício articulador do pensamento musical, Burmeister (1993, p. 118-119) recomenda ainda parcimônia e cuidado no uso da cadência, sob pena de produzir algo confuso e fora do domínio da arte.

Considerando a correspondência entre as cadências musicais e a pontuação textual e a correspondência entre as unidades textuais e musicais, os períodos, e considerando ainda que, no processo criativo musical, o texto antecede a própria elaboração musical, podemos compreender que a estrutura textual condiciona a estrutura musical, seu todo e suas partes. Burmeister (1993, p. 202, 203) reconhece nas obras de música três partes e, numa perspectiva retórica, as nomeia de exórdio (exordium), o corpo da poesia (corpus carminis) e fim (finis). Rivera acertadamente relaciona essa tripartição àquela proposta na Poética aristotélica e contrafeita nos Preceitos de poética musical (Praecepta musicae poeticae) de G. Dressler (1533-1580/9), obra não citada por Burmeister, mas certamente conhecida por ele, pois bastante difundida no universo das escolas latinas luteranas (Lateinschule), mesmo que de forma manuscrita. Ainda que esta divisão seja genérica, ela estabelece função para a parte inicial e final, tal como introdução e conclusão, e reúne como corpo da poesia tudo o que se coloca entre esses extremos. A quantidade de períodos que cada parte comporta é indefinida

Lídio e Hipolídio; os modos Frígio e Hipofrígio, para os assuntos lamentosos e dolorosos; para as coisas medianas e moderadas, os modos Jônico e Hipojônico. Embora Burmeister reconheça a existência de 14 modos diferentes, um modo autêntico e um modo plagal iniciados sobre cada uma das notas da escada diatônica, os modos iniciados pela nota Lá não são descritos por sua qualidade expressiva; já o modo autêntico iniciado pela nota Si (Hyperaeolius) e o modo plagal iniciado pela nota fá (Hyperphrygius) não são considerados úteis pela ausência da quinta justa entre a nota final do modo e seu quinto grau em sua estrutura diatônica, e por isso não são considerados nessa descrição.

${ }^{24}$ Resolutio cantilenae in affectiones est divisio cantilenae in periodos. (BURMEISTER, 1993, p. 202).

25 Nulla harmonia clausulis carere potest. Est enim clausula in harmonia, velut in corpore animato, anima. (BURMEISTER, 1993, p. 116). 
e depende de cada poesia, por sua quantidade de versos, ou incisos, frases e/ou períodos, conforme a divisão do texto planejada pelo compositor, e sua elaboração musical, pela forma de realização e repetição dessas partes. A função dessas partes intermediárias também se configura em cada poesia, conforme as possibilidades retoricamente concebidas, não se constituindo como partes fixas, mas como unidades facultativas, realizáveis conforme os objetivos do texto e suas condições de recepção.

Quando Burmeister define a Musica Poetica, concebe-a como "aquela parte da música que ensina a compor uma poesia em música, unindo sons melódicos em harmonia, ornamentados com os diversos afetos dos períodos, a fim de mover as almas e os corações humanos"26. Nesta definição, Burmeister faz referência aos afetos dos períodos e, em outras partes de seu tratado, faz referência aos períodos como afetos, como termos equivalentes ${ }^{27}$. No contexto retórico, segundo Quintiliano (2016, p. 540-541), ao período correspondem as ideias de ambitus, circumductum, continuatio (ordem ininterrupta) ou conclusio (período oratório, conclusão). Todos esses termos são usados como sinônimos e designam uma espécie de frase oratória fechada e concluída, uma unidade compositiva dotada de sentido completo, formada por incisos (incisa), definidos como pequenos membros de um período, e membros (membra), definidos como partes de um período ou versos de uma estrofe. O que diferencia os incisos dos membros é apenas a qualidade pequena atribuída ao primeiro. Num sintagma aumentativo, poderíamos considerar então a seguinte sequência: inciso, membro, período, na qual o subsequente sempre contém o antecedente. Burmeister não trata sobre os incisos e membros na discussão de sua poética, mas apenas de períodos, como as unidades que constituem o todo da obra musical e possibilitam sua fragmentação e racionalização.

Sobre a ideia dos afetos no contexto das artes retóricas, Quintiliano esclarece:

Destes, por sua vez, duas são as espécies: à primeira os gregos chamam de pathos, que nós, traduzindo de maneira correta e apropriada, dizemos "afeto"; à segunda, chamam de ethos, termo de que, pelo menos segundo penso, a língua romana carece: são chamados de costumes ${ }^{28}$.

Cícero, nas Discussões tusculanas (Tusculanae Disputationes), faz referência a uma "correta" definição latina do termo grego pathos da seguinte maneira:

\footnotetext{
${ }^{26}$ Musica Poetica est illa Musicae pars, quae carmen musicum docet conscribere, conjungendo sonos Melodiarum in Harmoniam, varijs periodorum affectionibus exornatam, ad animos hominum cordaque in varios motus flectenda. (BURMEISTER, 1993, p.16).

${ }^{27}$ Como no capítulo 15, que trata da análise musical, e propõe como quinta categoria analítica a "fragmentação de uma obra em afetos ou períodos" (resolutio carminis in affectiones, sive períodos) (BURMEISTER, 1993, p. 200201), ou como no capítulo 5 , que trata sobre as cadências, e as define por seu uso "na conclusão dos afetos melódicos, ou seja, dos períodos, e para a conclusão das próprias harmonias" (usum habens ad melodiarum affectiones [hoc est períodos] terminandum ipsamque harmoniam finiendum] (BURMEISTER, 1993, p. 106-107).

${ }^{28}$ Horum autem [sc. adfectuum] [...] duae sunt species: alteram Graeci pathos uocant, quod nos vertentes recte ac proprie adfectum dicimus, alteram ethos, cuiús nomine, ut ego quidem sentio, caret sermo Romanus: mores appellantur [...]. (QUINTILIANO, 2016, VI, 2, 8.)
} 
Auditor: Parece-me que a dor afeta o sábio.

M: Isso não vale para as demais perturbações da alma, os medos, os desejos, [os acessos de] cólera? De fato, eles entram, em termos gerais, na categoria que os gregos chamam de páthe. Eu poderia chamá-los de doenças, e isso seria uma tradução literal, mas não se enquadraria em nosso uso. É que comiserar-se, invejar, exultar, alegrar-se, tudo isso os gregos chamam de doenças, movimentos da alma que não obedecem à razão; por outro lado, penso que poderíamos, com correção, denominar esses mesmos movimentos da alma agitada de "perturbações", enquanto "doenças" estaria num sentido não muito usual [...]. ${ }^{29}$

A ideia do afeto, enquanto perturbação da alma do ouvinte provocada propositalmente pelo orador, como efeito calculado resultante da ação de proferir um discurso, conjuga-se com a ideia de período pelo limite que este impõe, enquanto unidade discursiva, para realização da perturbação. Ao utilizar os termos afeto e período como sinônimos, Burmeister provavelmente se orienta pelas possibilidades de equivalência entre ambos, que se efetuam na duração do período como o tempo de duração do afeto; no sentido e na forma de expressão da ideia contida no período, como a natureza do próprio afeto, por seu tipo, dignidade e intensidade; ou na finalidade ou função do período na obra como a causa final da perturbação por ele produzida.

Essa ideia é retomada em vários momentos do tratado de Burmeister, como no início do capítulo quatro, quando, ao tratar sobre a sintaxe musical, ele define a melodia nos seguintes termos: "Melodia é o período formado por uma sequência intervalar de notas, adaptada ou criada para produzir o movimento musical que provocará afetos (perturbações) num homem sensível à música"30. No texto latino original dessa definição, Burmeister faz uso dos termos correlatos affectio e affectus, criando aparente ambiguidade ao afirmar que a melodia é o affectio (período) que produz affectus (afeto). Essa ambiguidade pode ser resolvida pela relação de causa e efeito que fundamenta a analogia entre período e afeto, a partir da compreensão do período como melodia, ou seja, como sequência de notas adaptada de algo já existente ou criada como algo novo que produz movimento musical, um gesto sonoro estruturado, intencional e deliberado, com o objetivo de provocar perturbações no ouvinte, de gerar afeto. De outro modo, podemos considerar a analogia entre affectio e affectus pela relação entre potência e ato. O período (affectio) enquanto unidade musical, considerada em sua dimensão gramatical e retórica, em potência, distingue-se do afeto (affectus) enquanto ato, perturbação efetiva do ouvinte a quem o discurso sonoro se dirige.

\footnotetext{
${ }^{29}$ A. Videtur mihi cadere in sapientem aegrutudo. M. Num reliquae quoque perturbationes animi, formidines, libidines, iracundiae? Haec enim fere sunt eiusmodi, quae Graeci pathos appellant; ego poteram morbos et id verbum esset e verbo, sed in consuetudinem mostram non caderet: nam misereri, invidere, gestire, laetari, haec omnia morbos Graeci appellant, motus animi rationi non obtemperantes; nos autem hos eosdem motus concitati animi recte, ut opinor, perturbationes dixerimus, morbos autem non satis usitate [...]. (SCATOLIN, 2009. p. 127128).

30 Melodia est pro intervallorum ratione sonorum se invicem subsequentium affectio, ad modulamen, affectus in homine non plane amuso creans, parata, vel facta. (BURMEISTER, 1993, p. 56).
} 
Nesse sentido, o que é o período em potência - affectio - é inteligível somente em termos do que já é efetivamente o afeto em ato - affectus. Na ordem do devir, contudo, a potência precede a atualidade, pois o que é o afeto só pode vir a ser daquilo que pode ser o período e, sendo este o caso, o objeto correlato deve ser examinado em primeiro lugar. Pois o ato se remete a algo anterior a ele, justamente o objeto que lhe é correlato e correspondente, neste caso, ao período. Além disso, de acordo com a prática musical seiscentista, especialmente aquela polifônica, o período nunca será concebido como uma única melodia, mas como uma combinação de tantas melodias quantas forem as vozes/partes que constituem o todo da obra. Assim, considerar o período como melodia equivale a considerar, de forma metonímica, o todo por sua parte, o que não invalida a relação, mas ajuda a esclarecê-la. Além disso, neste conceito, Burmeister relaciona também a realização do efeito, da perturbação, à sensibilidade à música ou ao conhecimento musical, como indica a expressão in homine non plane amuso, que poderia ser traduzida literalmente como "num homem não sem sensibilidade à música" ou "num homem não sem conhecimento da música". Certamente, essa relação faz referência à capacidade intelectiva do discurso musical por parte do ouvinte, a partir do entendimento de que o efeito de um discurso só se realiza por meio da compreensão sensível e/ou racional daquilo que é comunicado com ele. O conhecimento da ou a sensibilidade para a linguagem musical, neste caso, é fundamental e garante a efetivação do processo comunicativo e a realização dos objetivos projetados pelo músico-orador.

A ideia do afeto como período, como citado anteriormente, é retomada também no capítulo cinco, que trata sobre as cadências, definidas por seu uso "na conclusão dos afetos melódicos (ou seja, dos períodos) e para a conclusão das próprias harmonias" ${ }^{31}$. Nesta definição, a melodia qualifica a ideia de afeto, que por sua vez é equiparada à ideia de período, transferindo a ele, de forma efetiva, a relação com a melodia. Nesse sentido, a relação entre período e afeto constitui um conceito mais complexo do que aquele que cada um dos termos separadamente poderia fornecer ao leitor do Musica Poetica: pelo viés do afeto, podemos reconhecer a unidade semântica daquilo que o músico-orador pretende comunicar, seja como ideia, seja como efeito; pelo viés do período, podemos compreender a unidade gramatical do discurso condicionada pelos limites da pontuação textual e musical. É dentro desses limites, inclusive, que a dimensão estilística do discurso musical se efetiva, conforme declara Burmeister no capítulo doze ao definir os ornamentos e figuras musicais:

O ornamento musical ou figura é o desenho musical, tanto em harmonia quanto em melodia, circunscrito em determinado período iniciado desde uma cadência e

\footnotetext{
31 Clausula [...] usum habens ad melodiarum affectiones (hoc est períodos) terminandum ipsamque harmoniam finiendum. (BURMEISTER, 1993, p. 106-107).
} 
concluído por uma cadência, que se distancia da razão composicional simples para assumir e vestir, com virtude, a veste ornada. ${ }^{32}$

Essa dimensão estilística, enquanto parte de uma concepção retórica mais ampla, regula a maneira da expressão musical, estabelecendo critérios para sua adaptação ao tipo de matéria, de público, lugar, ocasião e circunstância de recepção, como forma de garantir o cumprimento efetivo de seus objetivos. Nesses termos, Burmeister (apud BARTEL, 1997, p.96) condiciona o uso dos ornamentos e figuras musicais ao exercício do decoro poético (poeticum decorum), que é definido como a construção musical mais ornada e agradável resultante da consideração e interpretação do texto ${ }^{33}$. Conforme esse autor, o decoro poético opera justamente essa proporcionalidade entre a representação verbal e a musical, assim como o ajustamento da obra produzida às variantes que caracterizam as condições de sua recepção.

No contexto da produção musical seiscentista, que propõe a alteração da materialização sonora mais simples e direta do discurso, aquela produzida pelo orador, para torná-la mais persuasiva, por meio da ação do músico-orador, o compositor, aquele que opera a compositio, situa-se como causa eficiente desse processo de adaptação do discurso, de uma forma de expressão para a outra. A ele compete o estudo do texto, a base da operação musical, e sua adaptação sonora, fazendo uso de técnicas de invenção, medidas dispositivas e artifícios elocutivos, preservando o sentido do texto, sua finalidade, qualidade e inteligibilidade, em conformidade aos padrões e formas de expressão consolidados pela tradição.

Burmeister (1993, p. 200-203) finaliza a descrição de suas categorias analíticas justificando a prática da análise como forma de estudo dos artifícios presentes nas obras, que favoreça o uso deles como modelo para imitação. Em seu tratado, a imitação é definida como "o estudo e o empenho em conceber e moldar as poesias postas em música conforme os exemplos dos mestres compositores, que devem ser habilmente examinadas por meio de análise" ${ }^{34}$. A imitação pode ser geral ou específica. É geral quando diversos modelos e compositores são tomados como referência para imitação de invenção, disposição, ornamentação e elaboração contrapontística. É específica quando um único compositor é escolhido como modelo e, nesse caso, diz-se da composição que segue o estilo de Lasso, por exemplo, ou de Marenzio, quando ela imita a maneira particular desse ou daquele compositor de inventar e conectar ideias e períodos (BURMEISTER, 1993, p. 208-209).

\footnotetext{
32 Ornamentum sive figura musica est tractus musicus, tam in harmonia, quam in melodia, certa período, quae clausula initium sumit et in clausulam desinit, circumscriptus, qui a simplici compositionis ratione discedit, et cum virtute ornatiorem habitum assumit et induit. (BURMEISTER, 1993, p. 154-156).

33 Poeticum decorum est harmoniae ultra suavisonantem et harmonicam syntaxin ornatum ex textus explicandi exigentia addens.

34 Imitatio est studium et conamen mostra carmina musica ad artificum exempla, per analysin dextre considerata, effingendi et formandi. (BURMEISTER, 1993, p. 206-207).
} 
Segundo Burmeister (1993, p. 208-209), os verdadeiros e especialmente ilustres mestres, cujas obras qualquer um pode imitar são Clemens non Papa, Orlando di Lasso, Ivo de Vento, Alexander Utendal, Jacobus Regnart, Johannes Knöfel, Jacob Meiland, Antonio Scandello, André Pevernage, Leonhardt Lechner, Luca Marenzio e Johann Dressler. Cada um desses compositores se destaca pelo exercício de um dos quatro estilos existentes, que são o baixo, o elevado, o médio e o misto ${ }^{35}$. Meiland, Dressler e Scandelo destacam-se pelo exercício do estilo baixo; Clemens non Papa, Ivo de Vento, Regnart, Pevernage e Marenzio, pelo estilo médio; pelo estilo elevado ou sublime, os compositores Utendal, Knöfel e Lechner; pelo estilo misto, Orlando di Lasso.

Numa perspectiva pedagógica, Burmeister recomenda ao compositor iniciante que inicie sua formação pela imitação de obras pertencentes ao estilo baixo, siga pelo estilo médio, avance pelo elevado e finalize pelo misto. Recomenda ainda, numa linda metáfora, que o iniciante preserve essas categorias em mente, de maneira que, "ao começar a imitar, ele não se perca em confusão e puxe a âncora em face de um falso sinal, começando a velejar sem ter selecionado um bom timoneiro para o navio" ${ }^{36}$.

\section{Considerações finais}

As categorias analíticas propostas por Burmeister refletem o processo criativo concebido por ele, na medida em que elas foram elaboradas para ilustrar esse processo, colocando em evidência os artifícios, técnicas e processos que lhe são próprios, como forma de viabilizar aos compositores iniciantes o acesso a ele por meio do estudo do repertório referenciado. O fim último é a imitação dos modelos instituídos pela tradição, a manutenção das práticas e da ordem social. Nesses termos, podemos assumir que o estudo e a aplicação dessas categorias corresponde ao estudo do processo criativo, na medida em que o refazemos em sentido oposto, da obra acabada, resultante dos artifícios elocutivos, em direção aos materiais, lugares e procedimentos da invenção, como um processo de desconstrução, ou, mais propriamente, de decomposição. Ao final do Musica Poetica, Burmeister sintetiza esse processo criativo em dez princípios, como segue:

1. Para cada texto deve-se eleger um certo modo.

2. A harmonia deve possuir uma qualidade ou outra (natural ou transposta).

\footnotetext{
35 Para Burmeister (1993, p. 208-209), o estilo baixo caracteriza-se pelo predomínio do movimento por graus conjuntos e de combinações consonantes entre as vozes. O estilo elevado caracteriza-se pela introdução de intervalos mais amplos e pela abundante mistura de dissonâncias escondidas entre consonâncias. O estilo médio é aquele no qual prevalece um equilíbrio entre as qualidades do estilo baixo e do estilo elevado. O estilo misto é aquele no qual se adotam as qualidades dos outros três estilos de forma arbitrária, não simultaneamente, mas sucessivamente, conforme a natureza do texto que o compositor ornamenta harmonicamente.

${ }^{36}$ Discrimen futuro componistae habendum est, ne, cum primum imitari coeperit, confusione commissa sacram anchoram adverso bubone quase solvat, ventisque vela, certo navis gubernatore non selecto, committat. (BURMEISTER, 1993, p. 210).
} 
3. A quantidade, em relação aos sinais, não pode ser negligenciada (uso de notas negras).

4. As cadências devem ser usadas corretamente e de acordo com o modo.

5. De acordo com a necessidade do texto, o exordio deve ser elaborado à maneira de uma fuga ou outro ornamento correlato.

6. O movimento dos intervalos não pode ser abstruso, confuso.

7. A conexão das consonâncias não pode ser remota.

8. O sentido das palavras e das ideias deve ser realçado pelos ornamentos.

9. A aplicação do texto sob as notas deve ser bem cuidada, e não tumultuada.

10. A textura da obra não pode tender ao lacônico, e nem deve pesar pela excessiva prolixidade.

À primeira categoria analítica, a investigação do modo, correspondem o primeiro e o quarto princípios; à segunda categoria, a investigação do gênero da melodia, correspondem o sexto e o sétimo princípios; à terceira categoria, o tipo de polifonia, correspondem o terceiro e o décimo princípios; à quarta categoria, consideração da qualidade, corresponde o segundo princípio e, à quinta categoria, a divisão da obra em afetos ou períodos, correspondem o quarto, o quinto e o oitavo princípios. O nono princípio relaciona-se especificamente à dimensão ortográfica, aspecto gramatical importante que orienta o registro escrito da música, mas que não é considerado como parte do processo analítico, uma vez que não compete à análise a manuscritura da música, mas apenas sua leitura e interpretação. Por essa razão, ele não seria contemplado pelas categorias analíticas, mas apenas pelo processo criativo.

Com o objetivo de ilustrar a aplicação dessas categorias, ao final de sua exposição, Burmeister apresenta uma sintética análise do moteto intitulado In me transierunt, de Orlando di Lasso, sobre a qual já se tratou anteriormente. Palisca (2001) e Runke (1955) já se debruçaram sobre ela e apresentaram divergências significativas em sua compreensão, especialmente em relação à concepção da estrutura da obra, uma vez que o texto de Burmeister é bastante sintético e deixa lacunas que conduzem a equívocos. A interpretação dessa análise merece ainda atenção e debate, pois os estudos são ainda escassos e tendem a reproduzir anacronismos que pouco contribuem para a compreensão da obra por seus próprios termos.

As categorias analíticas de Burmeister pressupõem, em efetivo, a existência de uma lógica criativa (definida e representada aristotelicamente como análise categórica das matérias pelo juízo) e de uma retórica (definida como técnica elocutiva) que orienta a produção de efeitos com verossimilhança e decoro, para a persuasão dos destinatários pretendidos na situação para a qual a obra é projetada. Essa lógica criativa, para Burmeister, configura-se conforme cinco categorias, de modo, gênero, textura, qualidade e estrutura, que 
condicionam a composição musical desde sua invenção até sua elocução final. Burmeister propôs aos seus leitores seiscentistas que refizessem esse percurso, em ordem inversa, como forma de conhecer os artifícios utilizados na produção musical coeva e imitá-los. Hoje, podemos tomar essa proposição como forma de conhecer esse repertório e a teoria musical que o explica e dá sentido, cuidando para reconhecer nele seus próprios valores, que o legitimam como representativos de regimes específicos de representação discursiva.

\section{Referências}

AMBIEL, Aurea Helena de Jesus. Lamentationes Jeremiae Prophetae de Orlando di Lasso $=a$ aplicação da quinta categoria analítica de Joachim Burmeister. 2010. Tese (doutorado) Universidade Estadual de Campinas, Instituto de Artes, Campinas, SP, 2010.

ARISTÓTELES. Ética a Nicômaco. Madrid: Alianza Editorial, 2005.

ARISTÓTELES. Retórica. Lisboa: Imprensa Nacional Casa da Moeda, 2005.

ARISTÓTELES. Poética. São Paulo: Editora 34, 2017.

BARTEL, Dietrich. Musica Poetica - musical-rhetorical figures in German Baroque Music. Lincoln; London: University of Nebraska Press, 1997.

BURMEISTER, Joachim. Musical Poetics. New Haven; London: Yale University Press, 1993.

DRESSLER, Gallus. Praecepta Musicae Poeticae. Anotações não publicadas de 1563. Disponível em: http://www.chmtl.indiana.edu/tml/16th/DREPRA_TEXT.html. Acesso em: 14 out. 2019.

DUNSBY, Jonathan; WHITTALL, Arnold. Análise Musical na teoria e na prática. Curitiba: Editora da UFPR, 2011.

FABER, Heinrich. Ad musicam practicam introductio, non modo praecepta, sed exempla quoque ad usum puerorum accomodata, quàm breuissime continens. Nuremberg: In Officina Johannis Montani et Ulrici Neuber, 1550. Disponível em: http://www.chmtl.indiana.edu/tml/16th/FABMUS1. Acesso em: 10 out. 2019.

HORÁCIO. Sátiras. São Paulo: EDIPRO, 2011.

LISTENIUS, Nicolaus. Musica Nicolai Listenii ab authore denuo recognita multisque novis regulis et exemplis adaucta. Nuremberg: Petreius, 1549. Disponível em:

http://www.chmtl.indiana.edu/tml/16th/LISMUS. Acesso em: 13 set. 2019.

LOSSIUS, Lucas. Erotemata Dialecticae Et Rhetoricae Philippi Melanthonis. Witebergae: Hoffmannus, 1600. Disponível em: http://nbn-resolving.de/urn:nbn:de:bvb:12-bsb00083297-0. Acesso em: 08 out. 2019.

LUTERO, Martim. Da Autoridade Secular. São Leopoldo: Sinodal, 2017.

MCCRELESS, Patrick. Music and Rhetoric. In: CHRISTENSEN, Thomas (ed.). The Cambridge History of Western Music Theory. Cambridge: Cambridge University Press, 2008.

PALISCA, Claude. V. Studies in the history of Italian music and music theory. Oxford: Clarendon, 2001.

PEREIRA, Aires Manuel R. dos Reis. A Mousiké: das origens ao drama de Eurípedes. Lisboa:

Fundação Calouste Gulbenkian, 2001.

RETÓRICA a Herênio. São Paulo: Hedra, 2005.

QUINTILIANO, Marcos Fábio. Instituição oratória. Campinas: Editora da Unicamp, 2016.

RIVERA, B. V.; RUHNKE, M. Joachim Burmeister. In: SADIE, S. (org.). The New Grove 
Dictionary of Music and Musicians. 2. ed. London: Macmillan, 2001. v. 4.

RUHNKE, Martin. Joachim Burmeister: ein Beitrag zur Musiklehre um 1600. Kassel: Bärenreiter, 1955.

SCATOLIN, Adriano. A invenção no Do orador de Cícero: um estudo à luz de Ad Familiares I, 9, 23. Tese de Doutorado. Faculdade de Filosofia, Letras e Ciências Humanas, Universidade de São Paulo, 2009.

SILVA, Tiago Bentivoglio. Tradução e Comentário à 13aㅡ Olímpica de Píndaro. Dissertação de Mestrado. Universidade de São Paulo, Faculdade de Filosofia, Letras e Ciências Humanas, 2015.

SKINNER, Quentin. The foundations of modern political thought - volume two: the age of reformation. Cambridge: Cambridge University Press, 2004.

ZARLINO, Gioseffo. Le istitutioni harmoniche. Venetia: Appresso Francesco Senese, 1558. Disponível em: http://tmiweb.science.uu.nl/text/reading-edition/zarins58.html\#p082. Acesso em: 09 out. 2019. 